\title{
Garden centre customer attitudes to pollinators and pollinator-friendly planting
}

\author{
Veronica Renée Wignall ${ }^{\text {Corresp., }}{ }^{1}$, Karin Alton ${ }^{1}$, Francis L W Ratnieks ${ }^{1}$ \\ ${ }^{1}$ Laboratory of Apiculture \& Social Insects, School of Life Sciences, University of Sussex, Falmer, Brighton, East Sussex, United Kingdom \\ Corresponding Author: Veronica Renée Wignall \\ Email address: v.wignall@sussex.ac.uk
}

Growing nectar- and pollen-rich flowering plant varieties in domestic gardens and other greenspace is an important pro-environmental behaviour that supports pollinating insects. Wildlife gardening is popular in the UK; however, public attitudes and behaviour relating to planting for pollinators are currently not well understood. We investigated these through questionnaires and interviews with customers in five garden centres in Sussex, southeast England, a relevant and useful consumer group representing horticulturally-engaged members of the public. Garden centre customers had strongly positive attitudes and were motivated to plant for bees and other pollinators: most (77\%) grew pollinator-friendly varieties, while $64 \%$ would be more likely to buy a plant with a pollinator-friendly logo. Personal motivation to support pollinators was linked to a recent increase in personal and public awareness of their declines through (often negativistic) information from mass media sources. Practical implications of these findings in relation to the horticultural retail industry are discussed. 


\section{Garden centre customer attitudes to pollinators and pollinator-friendly}

2 planting

3 Veronica Renée Wignall ${ }^{1}$, Karin Alton ${ }^{1}$, Francis L. W. Ratnieks ${ }^{1}$

$4{ }^{1}$ Laboratory of Apiculture \& Social Insects, School of Life Sciences, University of Sussex,

5 Falmer, Brighton, East Sussex, United Kingdom, BN1 9QG

6

7 Corresponding author:

8 Veronica Wignall ${ }^{1}$

9

10 Email address: v.wignall@sussex.ac.uk

11

12

13

14

15

16

17

18

19

20 


\section{Abstract}

22

23 Growing nectar- and pollen-rich flowering plant varieties in domestic gardens and other

24 greenspace is an important pro-environmental behaviour that supports pollinating insects.

25 Wildlife gardening is popular in the UK; however, public attitudes and behaviour relating to

26 planting for pollinators are currently not well understood. We investigated these through

27 questionnaires and interviews with customers in five garden centres in Sussex, southeast

28 England, a relevant and useful consumer group representing horticulturally-engaged members of

29 the public. Garden centre customers had strongly positive attitudes and were motivated to plant

30 for bees and other pollinators: most (77\%) grew pollinator-friendly varieties, while $64 \%$ would

31 be more likely to buy a plant with a pollinator-friendly logo. Personal motivation to support

32 pollinators was linked to a recent increase in personal and public awareness of their declines

33 through (often negativistic) information from mass media sources. Practical implications of these

34 findings in relation to the horticultural retail industry are discussed.

\section{Introduction}

39 Growing varieties of flowering plants that support pollinating insects is one of the most effective

40 behaviours through which the general public can directly help these insects, which are

41 considered to be in decline in the UK and worldwide, in part due to reduced availability of

42 nectar- and pollen-producing flowers (Carvell et al., 2006; Potts et al., 2010; Vanbergen \& the 
43 Insect Pollinators Initiative, 2013; Sánchez-Bayo \& Wyckhuysbc, 2019). Gardens and other

44 private or community greenspace (eg. allotments, cemeteries) have been shown to provide an

45 important resource for flower-visiting insects in both rural (Bates et al., 2011; Samnegård,

46 Persson \& Smith, 2011) and particularly urban environments (Ahrné, Bengtsson \& Elmqvist,

47 2009; Gunnarsson \& Federsel, 2014; Baldock et al., 2019). Many UK residents engage in

48 wildlife gardening, an increasingly common pro-environmental behaviour (Gaston et al., 2007,

49 Goddard, Dougill \& Benton, 2013). Furthermore, in a survey of over 500 households in Leeds,

$5041 \%$ of participants stated that watching or attracting wildlife was an important reason for using

51 their garden (Goddard, Dougill \& Benton, 2013). However, public attitudes specifically towards

52 flower-visiting insects and supporting these in gardens or other green space, including through

53 planting attractive flowering plant varieties, has not been assessed to our knowledge.

54

55 One indicator that the British public are interested in bees and other pollinators is a high level of

56 recent participation in nationwide pollinator monitoring and citizen science programmes,

57 facilitated over the last decade through technology including widely available smartphone

58 applications. For example, in 2018, 482,915 records of bees were submitted by 23,755

59 participants in the 'Great British Bee Count' led by Friends of the Earth (UK); 73\% of these

60 sightings were made in gardens (Friends of the Earth (UK), 2018). Meanwhile, also in the last

61 decade, several online resources to engage and inform the public about gardening for bees and

62 other pollinating insects have been published by sources including Friends of the Earth (UK)

63 (www.friendsoftheearth.uk/bees/gardening-bees), the Wildlife Trusts

64 (www.wildlifetrusts.org/actions/plant-flowers-bees-and-pollinators) and the Royal Horticultural

65 Society (www.rhs.org.uk/advice/profile?PID=648). Being well-informed is a predictor of pro- 
66 environmental action (Easman, Abernethy \& Godley, 2018); therefore, it is possible that this

67 recent increase in availability of online information may have also led to a corresponding growth

68 in public interest in and motivation to plant for pollinators.

69

70 Members of the UK public commonly purchase plants from garden centres, horticultural retail

71 outlets that sell plants and gardening material. British garden centre customers spent $£ 1.4$ billion

72 on garden plants in 2016 (Horticultural Trades Association, 2017) and two thirds of adults visit a

73 garden centre at least once a year (Horticultural Trades Association, 2018). Customers in garden

74 centres represent a sample of the UK public that have an interest in gardening, many of whom

75 are likely regularly to plant ornamental flowering plants to varying extents, or have the potential

76 to do so. Therefore, this customer group is relevant and useful to understand the attitudes and

77 behaviours of horticulturally-engaged members of the public relating to pollinators and

78 pollinator-friendly planting. Improving our understanding of this through quantitative and

79 qualitative investigation is an important step in improving floral resources for pollinators.

80

81 Since garden centres are a major source of ornamental flowering plants to the general public, it is

82 also likely that increasing the availability and signposting of pollinator-friendly varieties could

83 have a direct positive impact on resource availability for pollinators throughout the UK.

84 However, one recent study revealed that many flowering plants on sale in garden centres were

85 not attractive to flower-visiting insects, in some instances even when labelled as pollinator-

86 friendly (Garbuzov, Alton \& Ratnieks, 2017). A second recent study identified pesticides in the

87 nectar and pollen of a large proportion of 'bee-friendly'-labelled plants sampled in garden

88 centres, in some cases at levels known to cause harm to bees (Lentola et al., 2017). This suggests 
89 that garden centres are not currently fulfilling a significant potential to facilitate pollinator-

90 friendly planting. The garden retail industry is influenced by socio-cultural drivers including

91 consumer pro-environmental attitudes and behaviour (Horticultural Trades Association, 2017),

92 therefore clarifying customer attitudes towards pollinators could have an important practical

93 implication in respect to the garden centre industry.

94

95 This study investigates the attitudes of customers in garden centres towards pollinators and

96 towards growing and purchasing plants that support flower-visiting insects. Our methods

97 simultaneously assess whether there is scope for garden centres to play a more active role in

98 facilitating pollinator-friendly planting. We collected questionnaire responses from 150 visitors

99 to five garden centres in Sussex, southeast England. The questionnaire gathered information

100 about (i) public attitudes to wildlife including pollinators and (ii) existing pro-environmental

101 behaviours relating to pollinators and knowledge about pollinator-friendly plants, including

102 awareness of plant labelling and information provided by garden centres. This was followed up

103 with 14 in-depth interviews with additional customers, to explore selected findings in more detail

104 using a qualitative research approach. Possible implications of the study findings are discussed,

105 including practical application in the garden retail industry.

108 Materials and Methods

110 Garden centres

111 
112 With permission from the managers, we gathered information from customers visiting five

113 garden centres in Sussex, England using questionnaires and interviews. These were typical of the

114 area, of similar sizes, and included both independent businesses $(n=2)$ and branches of larger

115 chains $(n=3)$. All seemed to have a similar customer base with no notable differences in

116 exclusivity or 'high-end' nature.

117

\section{Questionnaire design}

119

120 The questionnaires had three sections gathering (i) complementary information on the customer

121 (age, sex, reason for visit etc.), (ii) attitudes to wildlife including pollinators and existing pro-

122 environmental behaviours, and (iii) awareness of and attitude towards pollinator-friendly plants, 123 including plant labelling and information provided by garden centres. There was space at the end 124 for comments (Appendix B).

125

126 Garden centre visitor questionnaires and interviews

127

128 Questionnaires

129

130 In total, 150 questionnaires were completed, 30 per garden centre, in August and September

131 2018, with data gathered on one or two days mainly on weekdays (Table 1).

132

133 Customers were approached in the areas with plants for sale and asked if they would be happy to 134 take part in a research study for the University of Sussex. In order not to influence the responses, 
135 researchers did not mention pollinators, wildlife, plants or anything relevant to the study, nor did

136 they answer any questions about these topics while the participant was filling out the

137 questionnaire. If asked any questions, we explained that we had an information sheet on the

138 project to give them once they had completed the questionnaire.

139

140 We found no significant difference in either the proportions of male and female customers (Chi-

141 squared test, $\chi_{(1)}^{2}=0.106, P=0.745$ ) or the representation of different age groups (Fisher's exact

142 test, $P=0.905)$ between independent and chain stores, so all 150 questionnaire responses were

143 pooled for analysis. For certain questions respondents who ticked an incorrect number of boxes

144 were removed from the dataset, resulting in some question sample sizes of $<150$. Sample sizes

145 for questionnaire responses were 150 unless noted otherwise in the text (Results).

146

147 Interviews

148

149 After we had reviewed the questionnaire responses, we conducted 14 semi-structured interviews

150 with separate customers (who had not previously completed the questionnaire) in October 2018

151 in one garden centre, to provide further insights where our findings were interesting and/or led to

152 further questions (Goddard, Dougill \& Benton, 2013; Table 1). We based the interviews in

153 Wyevale garden centre, Lewes, as this is a branch of a popular large chain and was thought to

154 have a comprehensively representative customer demographic (Table 1). We approached

155 customers browsing in the garden centre and asked if they would be happy to spend 10-15

156 minutes answering some informal questions for a research project, in exchange for free

157 refreshments.

Peer] reviewing PDF | (2019:03:35800:1:1:NEW 2 May 2019) 
158

159 Interviewees were either in a pair ( $n=11$ pairs, 22 people) or single $(n=3$ people). The

160 interviewer (VW) informed the participant(s) that they would be recorded, and each was asked to

$161 \mathrm{read}$ and sign an information/consent form before the interview began. Each interview had three

162 sections (Appendix D). In Section 1, we asked the participant(s) to complete one customer

163 questionnaire. If they were a pair, we asked the keener gardener of the two to answer the

164 questionnaire. These 14 questionnaire responses were not included in our analysis of the 150

165 questionnaires completed previously. In Section 2, we asked for further details on their responses

166 to some of the questions (Qs: 6, 8, 9, 11, 12, 13, 14, 15, 16). In Section 3, we asked two further

167 questions not related to the questionnaire $(\mathrm{Q}+1$ : Has your awareness of/interest in bees and other

168 pollinators/pollinator-friendly plants changed over time? If so, could you tell me a little more

169 about this? and Q+2: Where do you think you receive most information about pollinators?).

170

171 Transcripts were manually analysed using qualitative inquiry (Saldaña, 2013). Themes were

172 drawn out using both in vivo and descriptive coding, to extract the most appropriate content and

173 essence of the interviews (Saldaña, 2013). After organising themes into categories and

174 subcategories, these were cross-referenced against quantitative survey findings and integrated

175 within these themes in the Results section.

176

\section{Ethical approval and garden centre permissions}

178

179 In each garden centre we obtained the manager's permission to survey customers on the

180 premises. On arrival we let the staff know that we were surveying customers on that day. 
182 All survey materials were approved by the University of Sussex Sciences \& Technology Cross-

183 Schools Research Ethics Committee (C-REC, project reference number ER/VW58/4). Interview 184 transcriptions and corresponding signed consent forms were given unique reference codes and 185 stored separately under password so that customers could withdraw their consent if they wished. 186 The customer questionnaire and information sheet, and interview questions are available in the 187 Appendices (B-D).

188

189 Pollinator-friendly logo size on plant labels

190

191 In three Garden Centres, including one in the five used for questionnaires (Rushfields Plant

192 Centre, Sussex) plus two additional (Brighton Wyevale, Sussex; Gates Garden Centre, Rutland), 193 we surveyed the pollinator-friendly logos present in the plant and bulb stock displayed at the 194 time, as well as seed packets on display (October 10, 2018). This was not to make a 195 comprehensive record of the logos used but provide additional information relating to Q15 in the 196 questionnaire Do you think the [pollinator-friendly] labels are visible enough? by measuring the 197 size of a representative sample of pollinator-friendly logos found on labels and packets in the 198 three centres as a proportion of the size of the overall label/packet.

199

200 We photographed any plant labels and bulb packets that included a pollinator-friendly logo with 201 a ruler for scale. As there were very large numbers of seed packets we haphazardly selected ten 202 packets with a pollinator-friendly logo for measurement. 
204 We found eight different pollinator-friendly logos at the time of our surveys in the three garden 205 centres (Fig. 1). The most commonly observed was the RHS (Royal Horticultural Society)

206 Perfect for Pollinators (Fig. $1 \mathrm{~h}$ ). Since this logo was much more commonly seen than the others, 207 we photographed a representative selection of plant labels that included it, including different 208 growers and label designs $(\mathrm{n}=35)$. In order to ensure other logos were represented, we made a 209 deliberate effort to find and photograph these. As such, the sample we collected does not reflect a 210 proportional distribution of logo types on the plant labels displayed in the centres at the time.

211 Sample sizes of the seven other logos found on plant labels were small (Fig. $1 a-g$, n: $a=2, b=$

$2122, c=1, d=3, e=2, f=3, g=1)$.

213

214 Logo area and total label size (measured as the visible part of the label, including any text that 215 directly accompanied the label were then measured using ImageJ (version 1.51, 2015). We also 216 noted whether there was any mention of pollinators on the reverse side of the label.

218 Statistical analysis

219

220 Contingency tests were used to compare the proportions of questionnaire respondents that chose 221 certain flowering plant features and those that were familiar with pollinator-friendly logos (male 222 vs female; interviewees vs overall questionnaire). When all values were $>5$, we used Chi-squared 223 tests, with a Yates continuity correction if any values were $<10$ (Yates, 1934). 
225 We analysed whether there was any difference in average logo size as a proportion of the total

226 label/packet area between plants, bulbs and seeds using a Kruskal-Wallis rank sum test since

227 data did not fit a parametric distribution.

228

229 All statistical analyses were performed using R Studio Version 1.1.463.

230

231 Results

232

233 Questionnaire respondents' characteristics

234

235 The majority of the 150 questionnaire respondents were over the age of $55(78 \%)$; most were 236 female (79\%; Fig. 2).

237

238 Almost all respondents had a garden (95\%). When buying plants, 68\% most often looked for 239 ornamental plants with flowers $(n=138 ; 12$ replies that had incorrectly ticked $>1$ box for this 240 question were removed), followed by trees or shrubs (20\%), vegetable/fruit plants (7\%), and 241 lastly indoor plants (5\%).

242

243 In a multiple response question asking why participants were visiting the garden centre that day,

244 the most common reason was to buy plants or seeds/bulbs (57\%), followed by leisure purposes,

245 for example browsing or visiting the cafe (52\%). Others were visiting to buy other gardening

246 items such as tools (22\%) or non-gardening items (16\%).

247 


\section{Customer attitudes towards wildlife and pollinators $(Q 7,8,9,10)$}

249

250 Most questionnaire respondents showed a positive interest in wildlife, with $146(97 \%)$ answering

251 that the decline of wildlife in Britain concerns them. Most did something in their garden or other

252 outside space to help wildlife (97\%).

253

254 In terms of pollinators specifically, almost all questionnaire respondents (97\%) thought that bees 255 and other pollinators were beneficial to their garden or other outdoor area. Most carried out 256 several of five pollinator-friendly actions listed in the questionnaire (mean $\pm \mathrm{SD}=2.55 \pm 1.20$

257 actions, range $=0-5)$. The most common was to grow pollinator-friendly plants $(77 \%$ of

258 participants), followed by using limited or no pesticides (64\%), providing flowers throughout the 259 year (57\%), leaving some areas unmown/unmanaged (37\%) and putting up bee hotels (19\%).

260 Only four people said they did not currently help bees and other pollinators in their garden or 261 outside area (Fig. $3 a)$.

262

263 Four interviewees mentioned that they disliked wasps. However, in general there was a positive 264 interest in pollinators that was often particularly focused on bees and butterflies. Many

265 interviewees even seemed to feel a psychological benefit of seeing bees and other insects in their 266 garden or outside area, with comments including: "I was very happy because I got a bees nest in 267 my compost and I liked that", "it can be quite therapeutic to sit and watch them [bees]" and "I 268 think bees are very important, well I know bees are very important, and we like watching the 269 bees". As well as this, there was a sense of a positive feeling towards environmental 270 stewardship, with comments such as: "you just think if it's keeping the natural balance of the 
271 ecosystem then it's a good thing"; "I love wildlife, I love the bees, I feed the bees, and anything

272 to help nature is better."

273

274 Interviewees also expressed concern for the wellbeing of pollinators, linking this to human and

275 planetary health. One commented "if we lose our bees, everything else follows suit, so it makes

276 sense to wake up, and you know, start doing more to protect the environment, down from plastic

277 to everything", another said "if we run out of bees, if the bees die we die, if they don't pollinate

278 our flowers and our shrubs and our fruits", and a third remarked "put it this way, if the bees go

279 the humans go".

280

281 Customer attitudes towards pollinator-friendly planting $(\mathbf{Q} 6,14)$

282

283 Bee- or pollinator-friendly $(53 \%, \mathrm{n}=145$ replies $)$ was one of three most and equally- important 284 features, excluding price, considered when buying flowering plants, with length of flowering $285(55 \%)$ and hardiness/low level of maintenance (56\%). There was no significant difference among 286 these three responses (Chi-squared test, $\left.\chi_{(2)}^{2}=0.574, P=0.754\right)$.

287

288

Many of the 150 questionnaire respondents said that if a plant has a 'pollinator-friendly' logo on 289 the label they would be more inclined to buy that plant (64\%). Almost a third of respondents answered that they would "maybe" be more inclined to buy a plant with a pollinator-friendly label (32\%); only six customers (4\%) answered that they would not (Fig. 3 b). 
293 In the interviews, most of the participants answering the questionnaire (13/14) also stated that 294 they would be more inclined to buy a plant that had a pollinator-friendly label. This might 295 depend on their original purchasing motive, for example: "I'd only buy it if it fell into my reasons 296 for buying the plant for that space at that time of year. But if it was a choice of two that were 297 equally..., I mean obviously you'd buy the pollinating one"; and in another interview "if it was 298 between two [plants] of the same colour and one was pollinating one then I would go for the 299 pollinator-friendly one... I might not actually but I would be tempted to". Several interviewees 300 referred to a pollinator-friendly logo as an "added benefit" or "bonus" that might make them 301 more inclined to purchase a pollinator-friendly plant $(\mathrm{n}=4$ interviews). For example: “We know 302 what we like, but if it says that on there then it's a bonus".

303

304 For other interview participants, the presence of a label would either assist their purchasing 305 306

\section{Perceived barriers to pollinator-friendly planting}

312

313

decision ("if that label was on one of the...[plants] it would help me choose"; "if I was looking at two plants and I couldn't make up my mind, then I would possibly go for the one that had that on [rather than] the other one didn' $t$ ') or provide a clear motive to buy one plant over another, for example: "When I look through the catalogue I always look to see what all the little symbols are, and if it's a bee-friendly one, definitely if it's a bee-friendly one I think I can justify buying it".

Interviewees identified certain barriers to planting for pollinators, including allergic reaction to bee stings: "I was stung by a bee, so I have to carry an epi-pen... we used to have the big area of wildflowers in the middle of the garden, but we don't have that anymore". Concern about 
316 children being stung was also discussed: "if you were asking us ten years ago we'd have been

317 going 'no I don't want bees, I've got three-year olds running round the garden'... I wonder

318 whether younger mums would be more concerned".

319

320 In one interview, price was mentioned as a potential barrier: "[we would be more inclined to buy 321 a plant with a pollinator-friendly label] as long as the cost didn't go up because of that, because 322 that's what happens... I think because they're marked as pollinator-friendly, they'd put the price 323 up".

324

325 Customer familiarity with pollinator-friendly plant logos (Q 12)

326

327 Just over half the questionnaire respondents were familiar with pollinator-friendly plant logos 328 (59\%). Proportionally more female participants (F: 64\%, $n=75 / 118)$ were familiar with the $329 \operatorname{logos}$ than male participants (M: 44\%, $\mathrm{n}=14 / 32$; Chi-squared test, $\chi^{2}{ }_{(1)}=4.094, P=0.043$ ). 330

331 Familiarity with pollinator-friendly plant logos among interviewees was slightly but not 332 significantly lower than in the overall questionnaire $(43 \%, \mathrm{n}=6 / 14, \mathrm{v} 59 \%, 89 / 150$; Chi-squared 333 test with Yates continuity correction, $\left.\chi_{(1)}^{2}=0.830, P=0.362\right)$.

334

335 Customer perception of pollinator-friendly plant $\log 0 \mathrm{~s}(\mathbf{Q} 13,15)$

336

337

Visibility 
339 Among a subset of 89 questionnaire respondents who were familiar with the logos and were,

340 therefore, able to comment reliably on visibility, $74 \%$ thought they were visible enough while

$34126 \%$ did not.

342

343 Several interviewees who were familiar with the logos commented that they were noticeable "if

344 you're looking for them" ( $\mathrm{n}=5$ of a total of 25 interviewees). For example: "you have to look for

345 them"; in another interview "you know if you're looking for something you're going to see it. If

346 you're not looking for it..." and in a third "well sometimes if you're looking, and it's obvious

347 they've got a pollinator-friendly label, well you see it don't you. But I don't always look for it'.

348

349 Reliability

350

$35170 \%$ of questionnaire respondents answered Yes to Question 13: Do you think these [pollinator-

352 friendly] labels are reliable sources of information, despite 28 of these customers having

353 answered that they were not familiar with the logos. $3 \%$ did not think they are reliable sources of

354 information, while $27 \%$ did not know.

355

356 Pollinator-friendly logo size as a proportion of plant labels

357

358 Mean logo size overall was $2.02 \pm 1.32 \%$ of the total label or packet area (median $=1.43, \mathrm{n}=65)$.

359 Proportional area of the pollinator-friendly plant logo was not significantly different between

360 plants $($ mean $\pm \mathrm{SD}=2.15 \pm 0.21 \%, \mathrm{n}=49)$, seeds $(1.73 \pm 0.26 \%, \mathrm{n}=10)$ and bulbs $(1.45 \pm 0.05, \mathrm{n}=$

3616 ; Kruskal-Wallis rank sum test, $\mathrm{H}_{(2)}=1.21, P=0.5455$; Table 2). The smallest proportional 
362 logo type was $1.08 \%$ of the total label area ("Good for Honey Bees", n = 1, Fig. $1 \mathrm{~g}$ ) and the

363 largest logo type was 7.58\% (“Bee friendly”, $\mathrm{n}=1$, Fig. 1 c)).

364

365 Most plant labels, seed packets and bulb packets with pollinator-friendly logos on the front did

366 not have any information about pollinators on the reverse of the label or packet (plants: $75 \%$;

367 seeds: 78\%; bulbs: 100\% (data given for labels for which reverse information was available);

368 Table 2).

369

370

Availability of advice and information in garden centres (Q16)

371

372 Question 16 asked questionnaire respondents whether they think garden centres offer enough

373 information about which plants are good for bees and other pollinators. The most common

374 response was $b$. No, and it would be useful to have more information (50\%), followed by a. Yes

375 (35\%). Just three answered c. No, but I don't mind (2\%), and 19 answered $d$. I don't know (13\%;

376 Fig. $3 c)$.

377

378 Interviewees answering the questionnaire also most commonly answered $b$. No, and it would be

379 useful to have more information $(64 \%, 9 / 14)$. Several commented on the potential for garden

380 centres to provide advice and information about pollinator-friendly plants. One interviewee

381 commented: "It's probably a place where to start, the garden centres, because it's probably

382 where people go and buy their plants, apart from markets and things." For another: "We love a

383 garden centre don't we, so I mean, well it's the best place to have it really isn't it', and a third

384 noted 'it's when you're buying the plants that you're thinking about pollinators, I mean not

385 when you're sitting in your sitting room".

Peer] reviewing PDF | (2019:03:35800:1:1:NEW 2 May 2019) 
387 A common theme was the lack of available information in garden centres, with several

388 interviewees making comments similar to this example: "I've never really walked round the

389 garden centre and seen anything about it". Some mentioned that the information might be there

390 if you looked for it or had a predetermined interest, for example: "It depends whether you want

391 to come in and you're interested in it or not, and if you're not, you're just going to go round the

392 garden centre buying the things that you want to buy".

393

394 Many felt that larger displays would be useful both to interest customers in pollinator-friendly

395 plants and to provide information. One interviewee remarked "I notice when the garden centre

396 has a special section for bee friendly, but I can't say I'm looking for logos" and another that "I

397 think you'd have to have it with some sort of big bee display for you to actually whilst you're

398 chatting and looking and kids and stuff, you'd have to have a reason to look at that section". One

399 interviewee noted the value of larger displays to "make information more prominent for older

400 eyes. Just to make people aware, just to bring the awareness, that's the main thing."

401

402 Several made suggestions such as leaflets, displays, guides, posters and grouping plants in a

403 'pollinator-friendly' section to provide information and attract customer interest.

404

405 Current media interest in pollinators

406

407 The most common source of interviewees' knowledge and awareness about pollinators was the

408 media, with one or more of television, 'the news', newspapers and radio mentioned in 12/13 
409 interviews in which the participant(s) were aware of pollinators. Several cited nature

410 programmes, documentaries and/or the popular weekly BBC television program 'Gardener's

411 World' while other sources included gardening books, education while growing up and

412 magazines. Social media was also acknowledged by one interviewee who received some of her

413 knowledge from Facebook. Only two of a total of 25 interviewees said they had received any

414 information about pollinators and/or pollinator-friendly plants in garden centres, despite many 415 participants being regular visitors.

416

417 We asked interviewees whether they felt there had been any general change in awareness about 418 pollinators over time. One had not been aware of pollinators prior to the interview, and in one 419 interview neither person in the pair gave a clear response to this question. One couple did not 420 feel their awareness of pollinators had changed. However, in 11 interviews, the participant(s) felt

421 there had been a recent increase in the quantity and availability of information about pollinators.

422 One said: "Definitely, in the last four, five years, there's been newspapers, television,

423 documentaries about it" while another commented "There's so much on the TV now, particularly

424 on sky channels and wildlife channels. It's everywhere".

425

426 Despite this, interview participants commented on a lack of reliable, comprehensive information: 427 “you've got to get your shock headlines out there to talk to people, but often there's not enough 428 back up information, or you've really got to make a concerted effort to go find out why and what 429 and how we can do anything about it". Several interviewees commented on how the news media 430 can be transient and unreliable, with comments such as: "now the whole buzz thing has gone to 431 plastic, and all of a sudden the bee awareness has just been pushed aside a bit"; "Occasionally 
432 there's some news, it comes up on the news about bees and the loss of bees, but then it's all a

433 one-day wonder". It was commonly noted that the public are often exposed to conflicting

434 information through the news, including about bees and other pollinators, “...so you think, well I

435 don't really know what the real story is".

436

437 Discussion

438

439 Our results show that UK garden centre customers have a strongly positive attitude towards 440 gardening for pollinators. Almost all (97\%) questionnaire respondents thought that bees and

441 other pollinators were beneficial to their garden, most (97\%) reported that they already take

442 some action to help these insects in their outside area, and many (53\%) prioritised pollinator-

443 friendly features when purchasing flowering plants. These overall conclusions were reinforced

444 through in-depth interviews. This is the first time to our knowledge that positive attitudes

445 towards wildlife gardening in the UK has specifically been shown to include pollinating insects;

446 although many British households actively encourage wildlife in their garden, this often chiefly

447 involves feeding birds (Gaston et al., 2007; Department for Environment Food \& Rural Affairs, 448 2009).

449

450 Positive attitudes towards pollinators and pollinator-friendly plants is likely to influence

451 consumer behaviour (eg. Wollaeger, Getter \& Behe, 2015; Rihn \& Khachatryan, 2016). This

452 may explain why, in our study, $96 \%$ of questionnaire respondents answered that they would

453 ('yes' 64\%; 'maybe' 32\%) be more inclined to buy a plant if it had a 'pollinator-friendly' label

454 (Fig 3 b). Insights from the interviews showed that, for some customers, knowing a plant was 
455 good for pollinators would justify their purchase or motivate them to buy a particular plant. For

456 others, a purchasing decision would depend on initial reasons for buying a plant, but knowing

457 one was pollinator-friendly would help them to choose between, for example, two similar

458 varieties.

459

460 In terms of practical actions to support pollinators, $77 \%$ of questionnaire respondents stated that

461 they currently grow pollinator-friendly plants (Fig $3 a$ ), although it was not clear whether they

462 had initially acquired these plants with the intention of supporting pollinators; it is possible that

463 this was often a by-product of varieties initially planted for other reasons. However, 53\% of

464 respondents considered bee- or pollinator-friendliness to be one of the three most important

465 features, excluding price, when buying flowering plants. A clear incentive to help bees was also

466 shown by a fifth of respondents who put up bee 'hotels'. These structures aim to provide nesting

467 habitats for solitary bees, although their efficacy is unclear (MacIvor \& Packer, 2015). Many

468 people also gardened with limited or no pesticides. While this is a common pro-environmental

469 behaviour that may reflect consumer awareness of pesticides' negative effects on pollinating

470 insects (Campbell, Khachatryan \& Rihn, 2017), participants' motivation for this action was not

471 investigated further in this study.

472

473 Public action to conserve pollinators is considered a necessary response to pollinator declines

474 (Cambridge Institute for Sustainability Leadership et al., 2017). Encouraging citizen action and

475 education forms a major part of the EU Pollinators Initiative (European Commission, 2018) and

476 several national-level pollinator strategies (Senapathi et al., 2017). Growing pollinator-friendly

477 varieties of flowering plants in gardens and other private or community greenspace is one of the 
478 most effective ways in which the general public can directly help flower-visiting insects. Flower

479 availability in both urban and countryside areas can often be reduced due to factors such as a

480 high proportion of impervious surfaces (McKinney, 2002) or intensive farming (Brassley, 2000;

481 Ollerton et al., 2014), whereas gardens can be relatively flower-rich, contain a high diversity of

482 plant species, and even provide a resource at times of the year when native flowers are not in

483 bloom (Smith, Warren \& Thompson, 2006; Stelzer et al., 2010; Baldock et al., 2015). Optimising

484 the supply of nectar and pollen in domestic gardens and other greenspace through choosing plant

485 varieties that attract insects (Garbuzov \& Ratnieks, 2014) is therefore increasingly important in

486 alleviating pollinator dietary stress, particularly since these areas comprise a relatively large total

487 area in the UK (Gaston et al., 2005).

488

489 Garden centres are well-placed to facilitate this both through supplying plant varieties that will 490 attract flower-visiting insects, and by delivering relevant advice and information to a substantial 491 customer base. Two thirds of British adults visit a garden centre at least once a year

492 (Horticultural Trades Association, 2018), and garden centre customers in Great Britain spent $493 £ 1.4$ billion on garden plants in 2016 (Horticultural Trades Association, 2017). Here, most 494 respondents were visiting the garden centre to purchase plants, seeds or bulbs (56.7\%), and when 495 buying plants most respondents looked for ornamental plants with flowers (68.1\%).

497 Despite this, evidence from this and previous research suggests that the potential for garden 498 centres to facilitate pollinator-friendly planting is not being met, despite clear customer interest 499 (Fig. 3). For example, it is possible for garden centres to use peer-reviewed scientific evidence to 500 select and market varieties of flowering plants that attract pollinators (Garbuzov \& Ratnieks, 
501 2014). However, many flowering plants on sale in garden centres are in fact not attractive to

502 flower-visiting insects, in some instances even when labelled 'pollinator-friendly' (Garbuzov,

503 Alton \& Ratnieks, 2017).

504

505 In this study, most customers perceived garden centres' provision of advice and information

506 about pollinator-friendly planting to be limited (Fig. 3 c). The majority of questionnaire

507 respondents thought that garden centres did not offer enough (52\%) and only two interviewees

508 had received any of their knowledge or information on this topic from garden centres compared

509 to other sources such as television, news media and nature programmes, which were cited several

510 times. This contrasted with a clear desire for more information, since half of all questionnaire

511 respondents thought that it would be useful for garden centres to offer more information. Several

512 interviewees even commented that garden centres would be the "best place" for advice about

513 which plants are attractive to pollinators since this is most useful in context, such as when people

514 are buying plants. Just over a third of questionnaire respondents thought there was enough

515 information in garden centres; of these, $72 \%$ were familiar with 'pollinator-friendly' logos. This

516 could indicate that a proportion of customers are generally well-informed on this issue, or

517 alternatively that customers who answered that garden centres do offer enough information are

518 basing this on the occurrence of pollinator-friendly logos.

519 Pollinator-friendly logos are one way in which garden centres advise customers about which

520 plants are good for pollinators. These 'eco-labels' can be successful marketing tools. Eye-

521 tracking technology has shown that customers who spent time looking at a pollinator-friendly

522 label on a plant were more likely to purchase it than those who did not view the label

523 (Khachatryan et al., 2017). In our study the majority of questionnaire respondents stated that they 
524 would be more likely to buy a plant that had a pollinator-friendly logo (64\%). However, $41 \%$

525 were not familiar with such logos. The logos tend to be small: here, mean pollinator-friendly

526 logo size on plant, bulb and seed labels was just $2.2 \%$ of the overall label or packet size, which

527 may explain why many respondents were not familiar with them.

528 Most respondents who were familiar with pollinator-friendly logos thought that they were visible

529 enough, possibly simply due to the fact that they had seen them. A number of interviewees

530 commented that these logos are noticeable if you are looking for them. This is consistent with

531 previous work investigating the potential efficacy of incentives for residential wildlife gardening,

532 in which interviewees commented that you have to "want to know" in order to find relevant

533 information (Goddard, Dougill \& Benton, 2013). Many garden centre customers, perhaps

534 particularly younger age groups with competing time demands, are likely to have a passive

535 approach to receiving information about which plants are attractive for pollinators, even if they

536 have a positive attitude towards pollinator conservation. This was summarised by one

537 interviewee: "I think you'd have to have it with some sort of big bee display for you to actually,

538 whilst you're chatting and looking and kids and stuff, you'd have to have a reason to look at that 539 section".

540

541 Since a lack of information has been shown to be a barrier to wildlife gardening here and in

542 previous research (Goddard, Dougill \& Benton, 2013; Campbell, Khachatryan \& Rihn, 2017),

543 this highlights a need for highly visible, accessible information to supplement pollinator-friendly

544 logos on plant labels. Interviewees suggested a range of options to provide information and

545 attract customer interest, including leaflets, displays, guides and posters. Several mentioned that

546 grouping plants in a 'pollinator-friendly' section with corresponding information would be 
547 helpful. Further suggestions based on our findings could be to i) increase the size of pollinator-

548 friendly logos to make them more visible and ii) include practical5 information about pollinators

549 in combination with these logos, since only a small proportion of plant, seed and bulb labels and

550 packets with logos had any mention of pollinators on the reverse of the packet (22.6\%; Table 2).

551

552 Customers spend a substantial length of time in garden centres, and under $10 \%$ of the UK spend 553 on garden plants is made online (Horticultural Trades Association, 2017). Unlike many other

554 industries where online retail success has caused traditional stores to be non-viable, the

555 experience of visiting a garden centre to purchase plants is clearly important to customers. This

556 opens the possibility for garden centres to provide obvious, accurate information about

557 pollinators that is available in context and at point-of-sale when customers are buying flowering

558 plants. In this study interviewees noted the usefulness of displays about other aspects of plant

559 qualities and care. It is possible that displays about pollinator-friendly plants could be easily

560 integrated into such pre-existing information infrastructure without significant cost, which might

561 provide a barrier to customers should it be reflected in pollinator-friendly plant prices (Campbell,

562 Khachatryan \& Rihn, 2017; this study).

563

564 We found that interviewees often spontaneously mentioned a positive emotional state associated 565 with seeing bees and other pollinators in their gardens. Gardens and other private outside areas, 566 including allotments, balconies and patios, can provide an important connection to nature, 567 particularly for people living in urban environments (Dunnett \& Qasim, 2000; Freeman et al., 568 2012; Cox et al., 2017). The benefit of wildlife gardening to personal psychological wellbeing 569 has previously been reported (Goddard, Dougill \& Benton, 2013), and a link between pollinators 
570 and emotional wellbeing in this study suggests that this may partly explain a personal motive for

571 gardening for pollinators.

572

573 Interestingly, many interviewees reported a recent increase in personal and public awareness of 574 pollinators, which was largely linked to a growth in the quantity of information published in print 575 and broadcast media. This was often negativistic, with several participants mentioning 'shock' or 576 'dramatic' headlines, the need to 'look after' pollinators such as bees and genuine concern about

577 their declines (recently reviewed in Sánchez-Bayo, F., \& Wyckhuysbc, 2019). This is similar to a 578 recent survey of environmental professionals and members of the British public which found a 579 large proportion of participants gained their information from mainstream media sources 580 (Easman, Abernethy \& Godley, 2018). In this study, individuals that were more concerned about 581 the marine environment were more likely to engage with pro-environmental actions to minimise 582 their personal impact (Easman, Abernethy \& Godley, 2018). It is likely that higher awareness of 583 and concern for pollinators would contribute to gardeners' personal motivation to encourage 584 pollinating insects. Concern for the status of pollinators may also have added to reported feelings 585 of happiness associated with seeing them in their outside area, since humans disproportionately 586 value rarity, which has been linked to increased interest in rare and threatened animal species 587 (Angulo \& Courchamp, 2009).

588

589 Awareness of pollinators and factors associated with their declines can influence plant 590 purchasing decisions based on pro-environmental attributes. In one study, consumers who were 591 aware of neonicotinoid pesticides, which have gained widespread media attention due to their 592 negative effects on insect pollinator health (reviewed in Van der Sluijs et al., 2013), were 
593 significantly more likely to buy plants labelled 'neonic-free' than those who were not aware 594 (Rihn \& Khachatryan, 2016). A taste for sustainable products has been identified as a major 595 socio-cultural driver in the garden centre retail industry by the Horticultural Trade Association 596 (HTA). For example, it is becoming important to meet a growing demand for alternatives to 597 plastic and peat, materials considered to be environmentally unsustainable, due to increasing 598 customer antipathy (Horticultural Trades Association, 2017). Here, several interviewees 599 described pollinator-friendly qualities as an 'added bonus' to plants they might purchase 600 primarily for other reasons. While this is a positive step, it also suggests that more could be done 601 to harness a clear motivation of garden centre customers to support pollinators, for example by 602 specifically advertising pollinator-friendly features to drive sales of these plants. Investigating 603 whether featuring pollinator-friendly qualities as a primary attraction would increase sales of 604 these plants compared to $i$ ) the same but un-labelled pollinator-friendly or ii) similar non605 pollinator-friendly varieties is a logical next step, since this could show the empirical value of 606 this type of marketing for garden centres themselves.

607

\section{Conclusions}

609

610 Growing pollinator-friendly varieties of flowering plants is one of the most effective ways in

611 which members of the public can directly help bees and other pollinators, which are known to be

612 in decline in the UK (eg. Carvell et al., 2006) and globally (Potts et al., 2010; Sánchez-Bayo \&

613 Wyckhuysbc, 2019). It is therefore important to understand public attitudes towards planting for

614 pollinators; however, this has not been directly studied as far as we are aware. This study

615 investigates garden centres customers' attitudes towards pollinators and pollinator-friendly 
616 planting, since this relevant and important consumer group represents members of the UK public

617 who are actively engaged in gardening. We show for the first time that customers have, in

618 general, a strong current interest in and positive attitude towards pollinating insects, which

619 translates into an impetus to plant pollinator-friendly plant varieties in private gardens or other

620 outdoor areas. Facilitating this could have a real impact on provision of floral resources for

621 pollinating insects, since gardens make up a large area of the UK (Gaston et al., 2005), and are

622 increasingly important sources of nectar and pollen for pollinators particularly in urban areas

623 (Baldock et al., 2019).

624

625 We also suggest that our findings are relevant to the horticultural retail industry, since provision

626 of evidence-based advice and information about pollinators and pollinator-friendly planting, as

627 well as promotion of such plants, could potentially be increased without substantial involved

628 costs to garden centres. We speculate that this would be likely to benefit sales due to a strong

629 customer interest, although this deserves further study; as well as having a positive effect on the 630 pollinators themselves.

631

632 Acknowledgements

633

634 The authors would like to thank the management team of each garden centre in this study,

635 particularly Paul Cooke (Wyevale, Lewes), Tom and Phil Cottingham (Staverton Nursery),

636 Michael Edmondson (Hillier, Hailsham), Kathryn Hillman (Rushfields Plant Centre) and Gary

637 West (Notcutts, Ditchling) for their assistance and kind permission to carry out questionnaire 
638 surveys and interviews with customers on their premises. We also thank Thomas Green for his

639 valuable help in data collection.

640

641

642 References

643

644 Ahrné, K., Bengtsson, J., \& Elmqvist, T. (2009). Bumble Bees (Bombus spp) along a gradient of

645 increasing urbanization. PLOS ONE, 4(5), e5574. https://doi.org/10.1371/journal.pone.0005574

646

647 Angulo, E., \& Courchamp, F. (2009). Rare species are valued big time. PLOS ONE, 4(4), e5215.

648 https://doi.org/10.1371/journal.pone.0005215

649

650 Baldock, K. C. R., Goddard, M. A., Hicks, D. M., Kunin, W. E., Mitschunas, N., Osgathorpe, L.

651 M., Potts, S. G., Robertson, K. M., Scott, A. V., Stone, G. N., Vaughan, I. P., \& Memmott, J.

652 (2015). Where is the UK's pollinator biodiversity? The importance of urban areas for flower-

653 visiting insects. Proceedings of the Royal Society B, 282(1803), 20142849.

654 https://doi.org/10.1098/rspb.2014.2849

655

656 Baldock, K. C. R, Goddard, M. A., Hicks, D. M, Kunin, W. E., Mitschunas, N., Morse, H., 657 Osgathorpe, L. M., Potts, S. G., Robertson, K. M., Scott, A. V., Staniczenko, P. P. A., Stone, G.

658 N., Vaughan, I. P., \& Memmott, J. (2019). A systems approach reveals urban pollinator hotspots 659 and conservation opportunities. Nature Ecology \& Evolution, Article.

660 https://doi.org/10.1038/s41559-018-0769-y

661

662 Bates, A. J., Sadler, J. P., Fairbrass, A. J., Falk, S. J., Hale, J. D., Matthews, T. J. (2011).

663 Changing Bee and Hoverfly Pollinator Assemblages along an Urban-Rural Gradient. PLOS

664 ONE, 6(8): e23459. https://doi.org/10.1371/journal.pone.0023459

665 
666 Brassley, P. (2000). Output and Technical Change in Twentieth-Century British Agriculture. The 667 Agricultural History Review, 48(1), 60-84.

668

669 Cambridge Institute for Sustainability Leadership, Fauna \& Flora International, University of 670 East Anglia, \& UN Environment World Conservation Monitoring Centre (UNEP-WCNC).

671 (2017). The pollination deficit: Towards supply chain resilience in the face of pollinator decline 672 [Report]. Retrieved November 112018 from https://www.cisl.cam.ac.uk/resources/natural673 resource-security-publications/the-pollination-deficit

674

675 Campbell, B., Khachatryan, H., \& Rihn, A. (2017). Pollinator-friendly plants: reasons for and 676 barriers to purchase. HortTechnology, 27(6): 831-839.

677 https://doi.org/10.21273/HORTTECH03829-17

678

679 Carvell, C., Roy, D. B., Smart, S. M., Pywell, R. F., Preston, C. D., \& Goulson, D. (2006).

680 Declines in forage availability for bumblebees at a national scale. Biological Conservation, 681 132(4): 481-489. https://doi.org/10.1016/j.biocon.2006.05.008

682

683 Cox, D. T. C., Shanahan, D. F., Hudson, H. L., Fuller, R. A., Anderson, K., Hancock, S., \& 684 Gaston, K. J. (2017). Doses of nearby nature simultaneously associated with multiple health 685 benefits. International Journal of Environmental Research and Public Health, 14(2), 172-185. 686 https://doi.org/10.3390/ijerph14020172

687

688 Department for Environment Food \& Rural Affairs. (2009). Defra Public Attitudes Survey 2009. 689 Retrieved November 212018 from 690 https://webarchive.nationalarchives.gov.uk/20110318145930/http://www.defra.gov.uk/evidence/ 691 statistics/environment/biodiversity/25-wildlife-2010.htm

692

693 Dunnett, N., \& Qasim, M. (2000). Perceived benefits to human well-being of urban gardens.

694 HortTechnology, 10(1): 40-45. https://doi.org/10.21273/HORTTECH.10.1.40

695 
696 Easman, E. S., Abernethy, K. E., \& Godley, B. J. (2018). Assessing public awareness of marine 697 environmental threats and conservation efforts. Marine Policy, 87: 234-240.

698 https://doi.org/10.1016/j.marpol.2017.10.030

699

700 European Commission. (2018). EU Pollinators Initiative: Communication from the Commission 701 to the European Parliament, the Council, the European Economic and Social Committee and the 702 Committee of the Regions. Retrieved November 262018 from

703 http://ec.europa.eu/environment/nature/conservation/species/pollinators/index_en.htm 704

705 Freeman, C., Dickinson, K. J. M., Porter, S., \& van Heezik, Y. (2012). "My garden is an 706 expression of me": Exploring householders' relationships with their gardens. Journal of 707 Environmental Psychology, 32(2), 135-143. https://doi.org/10.1016/j.jenvp.2012.01.005 708

709 Friends of the Earth (UK). (2018). The Great British Bee Count [homepage]. Retrieved February 710 52019 from https://friendsoftheearth.uk/bee-count

711

712 Garbuzov, M., \& Ratnieks, F. L. W. (2014). Quantifying variation among garden plants in 713 attractiveness to bees and other flower-visiting insects. Functional Ecology, 28(2), 364-374.

714 https://doi.org/10.1111/1365-2435.12178

715

716 Garbuzov, M., Alton, K., \& Ratnieks, F. L. W. (2017). Most ornamental plants on sale in garden 717 centres are unattractive to flower-visiting insects. PeerJ, 5: e3066.

718 https://doi.org/10.7717/peerj.3066

719

720 Gaston, K. J., Warren, P. H., Thompson, K., \& Smith, R. M. (2005). Urban domestic gardens

721 (IV): the extent of the resource and its associated features. Biodiversity \& Conservation, 14 (14):

$722 \quad 3327-3349$

723

724 Gaston, K. J., Fuller, R. A., Loram, A., MacDonald, C., Power, S., \& Dempsey, N. (2007).

725 Urban domestic gardens (XI): variation in urban wildlife gardening in the United Kingdom.

726 Biodiversity and Conservation, 16(11), 3227-3238. https://doi.org/10.1007/s10531-007-9174-6 
727

728 Goddard, M. A., Dougill, A. J., \& Benton, T. G. (2013) Why garden for wildlife? Social and

729 ecological drivers, motivations and barriers for biodiversity management in residential

730 landscapes. Ecological Economics, 86: 258-273. https://doi.org/10.1016/j.ecolecon.2012.07.016

731

732 Gunnarsson, B., \& Federsel, L. M. (2014). Bumblebees in the city: abundance, species richness

733 and diversity in two urban habitats. Journal of Insect Conservation, 18(6): 1185-1191.

734 https://doi.org/10.1007/s10841-014-9729-2

735

736

Horticultural Trades Association. (2017). HTA Garden Retail Market Analysis Report. Retrieved

737 August 172018 from marketinfo@hta.org.uk via https://hta.org.uk/learn-develop/market-

738 information/garden-market-analysis.html

739

740 Horticultural Trades Association. (2018). Garden Industry Statistics [webpage]. Retrieved

741 August 252018 from https://hta.org.uk/learn-develop/market-information/garden-statistics.html

742

743 Khachatryan, H., Rihn, A.L., Campbell, B., Yue, C., Hall, C., \& Behe, B. (2017). Attention to

744 eco-labels predicts consumer preferences for pollinator friendly plants. Sustainability, 9(10):

745 1743-1757. https://doi.org/10.3390/su9101743

746

747 Lentola, A., David, A., Abdul-Sada, A., Tapparo, A., Goulson, D., \& Hill, E. M. (2017).

748 Ornamental plants on sale to the public are a significant source of pesticide residues with

749 implications for the health of pollinating insects. Environmental Pollution, 228: 297-304.

750 https://doi.org/10.1016/j.envpol.2017.03.084

751

752 MacIvor, J. S., \& Packer, L. (2015). "Bee Hotels" as tools for native pollinator conservation: a

753 premature verdict? PLOS ONE, 10(3), e0122126. https://doi.org/10.1371/journal.pone.0122126

754

755 McKinney, M. L. (2002). Urbanization, Biodiversity, and Conservation: The impacts of

756 urbanization on native species are poorly studied, but educating a highly urbanized human

757 population about these impacts can greatly improve species conservation in all ecosystems.

Peer) reviewing PDF | (2019:03:35800:1:1:NEW 2 May 2019) 
758 BioScience, 52(10), 883-890. https://doi.org/10.1641/0006-

759 3568(2002)052[0883:UBAC]2.0.CO;2

760

761 Ollerton, J., Erenler, H., Edwards, M., \& Crockett, R. (2014). Extinctions of aculeate pollinators

762 in Britain and the role of large-scale agricultural changes. Science, 346(6215), 1360-1362.

763 https://doi.org/10.1126/science.1257259

764

765 Potts, S. G., Biesmeijer, J. C., Kremen, C., Neumann, P., Schweiger, O., \& Kunin W. E. (2010).

766 Global pollinator declines: trends, impacts and drivers. Trends in Ecology \& Evolution, 25(6):

767 345-353. https://doi.org/10.1016/j.tree.2010.01.007

768

769 Rihn, A., \& Khachatryan, H. (2016). Does consumer awareness of neonicotinoid insecticides

770 influence their preferences for plants? HortScience, 51(4): 388-393.

771

772 Saldaña, J. (2013). The Coding Manual for Qualitative Researchers. Los Angeles: SAGE

773 Publications.

774

775 Samnegård, U., Persson, A. S., \& Smith, H. G. (2011). Gardens benefit bees and enhance

776 pollination in intensively managed farmland. Biological Conservation, 144(11): 2602-2606.

777 https://doi.org/10.1016/j.biocon.2011.07.008

778

779 Sánchez-Bayo, F., \& Wyckhuysbc, K. A. G. (2019) Worldwide decline of the entomofauna: A 780 review of its drivers. Biological Conservation, 232: 8-27.

781 https://doi.org/10.1016/j.biocon.2019.01.020

782

783 Senapathi, D., Goddard, M. A., Kunin, W. E., \& Baldock, K. C. R. (2017). Landscape impacts 784 on pollinator communities in temperate systems: evidence and knowledge gaps. Functional 785 Ecology, 31(1), 26-37. https://doi.org/10.1111/1365-2435.12809 
787 Smith, R. M., Warren, P. H., \& Thompson., K. (2006). Urban domestic gardens (VI):

788 environmental correlates of invertebrate species richness. Biodiversity \& Conservation, 15(8):

789 2415-2438. https://doi.org/10.1007/s10531-005-2784-y

790

791 Stelzer, R. J., Chittka, L., Carlton, M., \& Ings, T. C. (2010). Winter Active Bumblebees (Bombus

792 terrestris) Achieve High Foraging Rates in Urban Britain. PLOS ONE, 5(3), e9559.

793 https://doi.org/10.1371/journal.pone.0009559

794

795 Vanbergen, A. J., \& the Insect Pollinators Initiative. (2013). Threats to an ecosystem service:

796 pressures on pollinators. Frontiers in Ecology and the Environment, 11(5), 251-259.

797 https://doi.org/10.1890/120126

798

799 Van der Sluijs, J. P., Simon-Delso, N., Goulson, D., Maxim, L., Bonmatin, J-M., \& Belzunces, 800 L. P. (2013). Neonicotinoids, bee disorders and the sustainability of pollinator services. Current 801 Opinion in Environmental Sustainability, 5(3-4): 293-305.

802 https://doi.org/10.1016/j.cosust.2013.05.007

803

804 Wollaeger, H. M., Getter, K. L., \& Behe, B. K. (2015). Consumer preferences for traditional, 805 neonicotinoid-free, bee-friendly, or biological control pest management practices on floriculture 806 crops. HortScience, 50(5): 721-732.

807 


\section{Table $\mathbf{1}$ (on next page)}

Details of five garden centres where questionnaires and interviews were conducted.

Three were branches of a larger chain of garden centres $\left({ }^{a}\right)$ and two were independents with only a single garden centre $\left({ }^{b}\right)$. All were in Sussex. Dates of customer surveys and interviews are shown by location 


$\begin{array}{lll}\text { Garden Centre } & \text { Surveys } & \text { Interviews }\end{array}$

$\begin{array}{cc}\text { Wyevale }^{\mathrm{a}} & n=30 ; 5 \text { September } \\ \text { Newhaven Road, Kingston, Lewes, BN7 3NE } & 2018 \\ \text { Hillier }^{\mathrm{a}} & n=30 ; 15 \text { August 2018 }\end{array}$

Hailsham Road, Pevensey, BN24 5BS

Notcutts $^{\mathrm{a}}$

Common Ln, Ditchling, Hassocks, BN6 8TN

Stavertons Nursery ${ }^{\mathrm{b}}$

Eastbourne Road, Halland, BN8 6PU

Rushfields Plant Centre ${ }^{\mathrm{b}}$

2

3

4

5

6

7

8

9

10

11

12

13

14

15

16

17 $n=30 ; 13 \& 15$

September 2018 


\section{Table 2 (on next page)}

Wildlife-friendly logo sizes on plant, seed and bulb labels/packets.

Average pooled measurements of pollinator- and wildlife-friendly plant logos and the plant labels $(n=49)$ and packets of seeds $(n=10)$ and bulbs $(n=6)$ on which they were found. Values are given as mean \pm sem. Any mention of pollinators on the label or packet reverse is indicated for those labels/packets for which this information was available. Logo types (a-h) are shown in Fig. 3. 
1

2

\begin{tabular}{|c|c|c|c|c|c|c|}
\hline & $n$ & $\begin{array}{c}\text { Logo } \\
\text { types } \\
\text { present }\end{array}$ & $\begin{array}{c}\text { Mean logo } \\
\text { area } \\
\left(\mathrm{mm}^{2}\right)\end{array}$ & $\begin{array}{l}\text { Mean total } \\
\text { label/packet } \\
\text { size }\left(\mathrm{mm}^{2}\right)\end{array}$ & $\begin{array}{c}\text { Mean logo area as } \\
\text { proportion of mean } \\
\text { total label/packet area } \\
(\%)\end{array}$ & $\begin{array}{l}\text { Mentions } \\
\text { pollinators on } \\
\text { label/packet } \\
\text { reverse? }\end{array}$ \\
\hline Plants & 49 & $\begin{array}{l}a, b, c, d \\
e, f, g, h\end{array}$ & $168 \pm 16.9$ & $8495 \pm 663$ & $2.15 \pm 0.21$ & Yes $=12 / 47$ \\
\hline Seeds & 10 & $a$ & $217 \pm 36.6$ & $12291 \pm 387$ & $1.73 \pm 0.26$ & Yes $=2 / 9$ \\
\hline Bulbs & 6 & $a$ & $435.2 \pm 56$ & $30377 \pm 4188$ & $1.45 \pm 0.05$ & No \\
\hline
\end{tabular}




\section{Figure 1}

Eight wildlife-friendly plant logos (a-h) found on plant labels in three garden centres. Photographs credit: Veronica Wignall
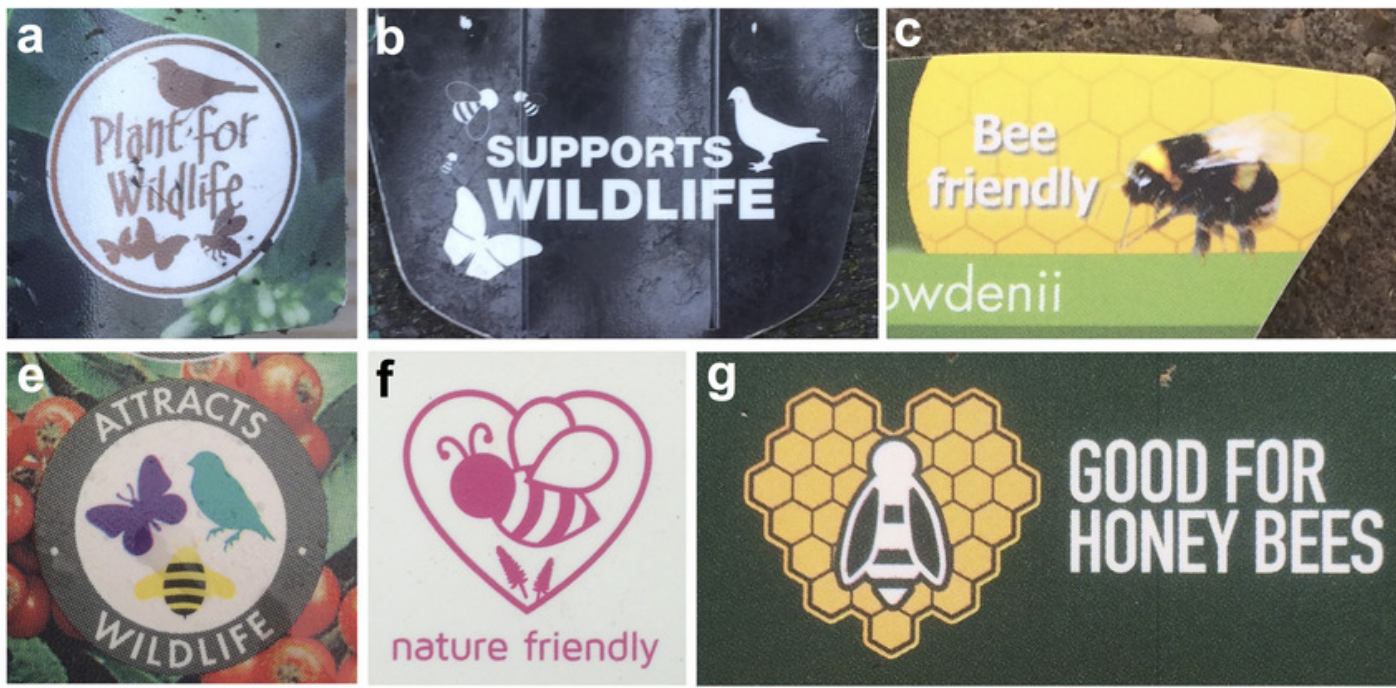

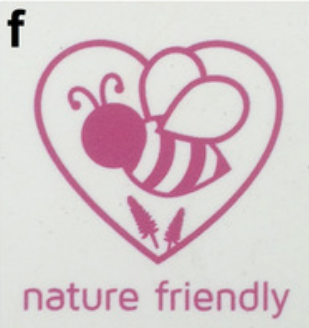

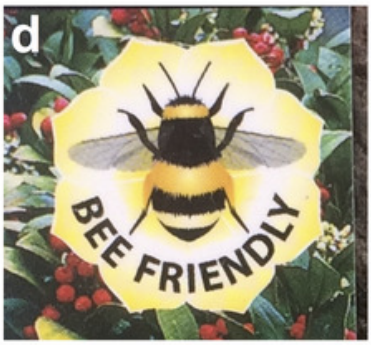

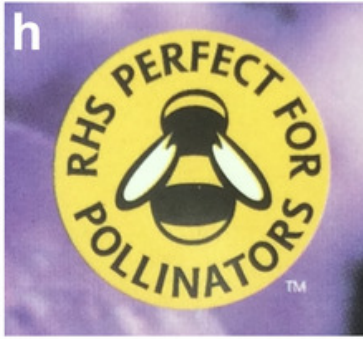


Figure 2

Questionnaire respondent characteristics.

Age and sex distribution of garden centre customers who answered the questionnaire $(n=$ 150). 


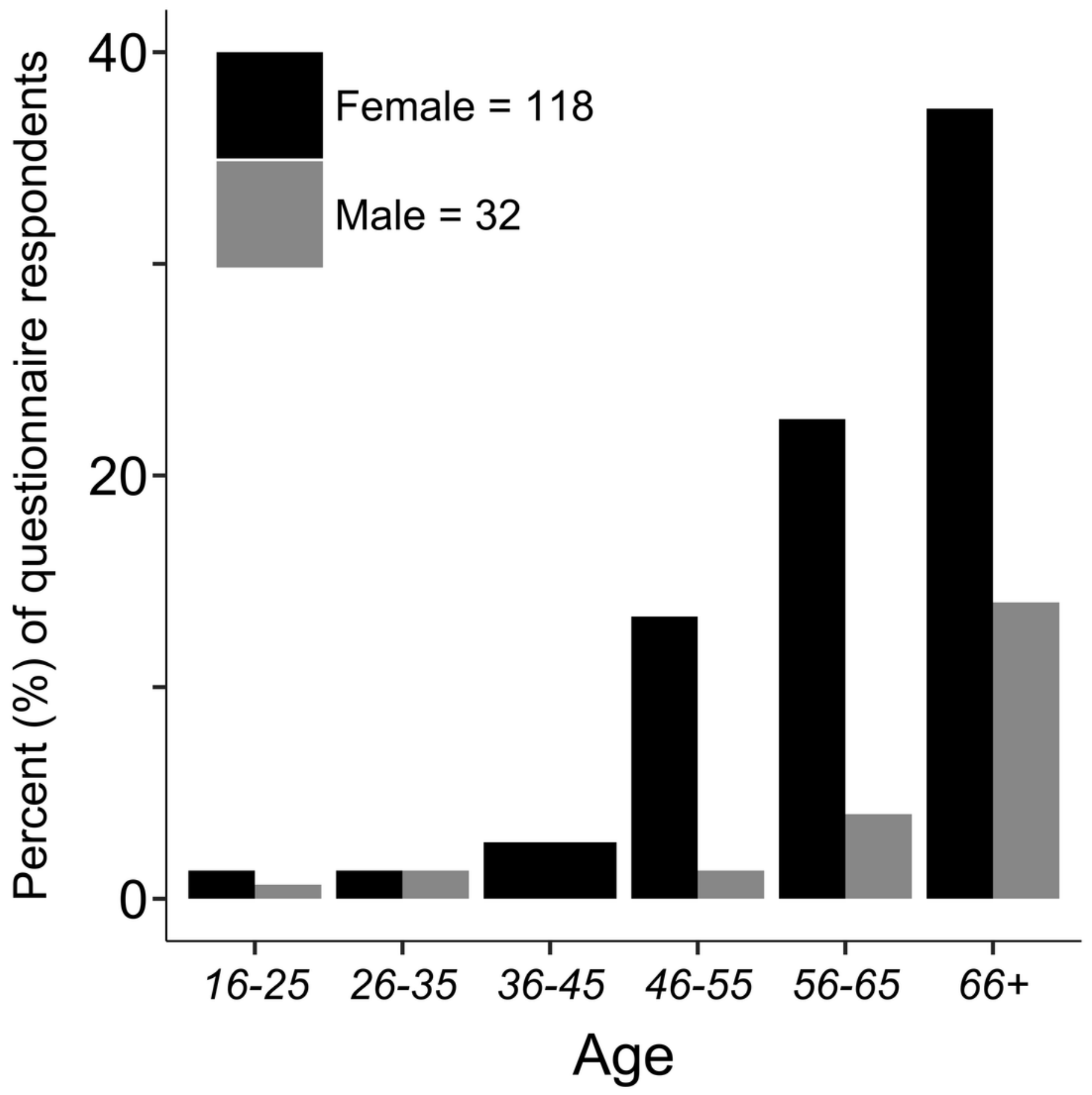




\section{Figure 3 (on next page)}

Garden centre customers' engagement and interest in pollinator-friendly gardening, compared to their perception of information provision by garden centres.

Grey horizontal bars show the percent of questionnaire responses for each answer to three questions in (a) Question 10 "How do you help bees and other pollinators in your outdoor area? Tick all that apply to you", (b) Question 14 "If a plant has a pollinator-friendly label would you be more inclined to buy that plant"and (c) Question 16 "Do you think garden centres offer enough information about which plants are good for bees and other pollinators". Response details are to the left of each bar. Counts are shown within bars. Sample size was $n=150$ customers for each question. Questions 10 was a multiple choice question. 
(a) Q10. How do you help bees and other pollinators in your outdoor area?

Tick all that apply to you

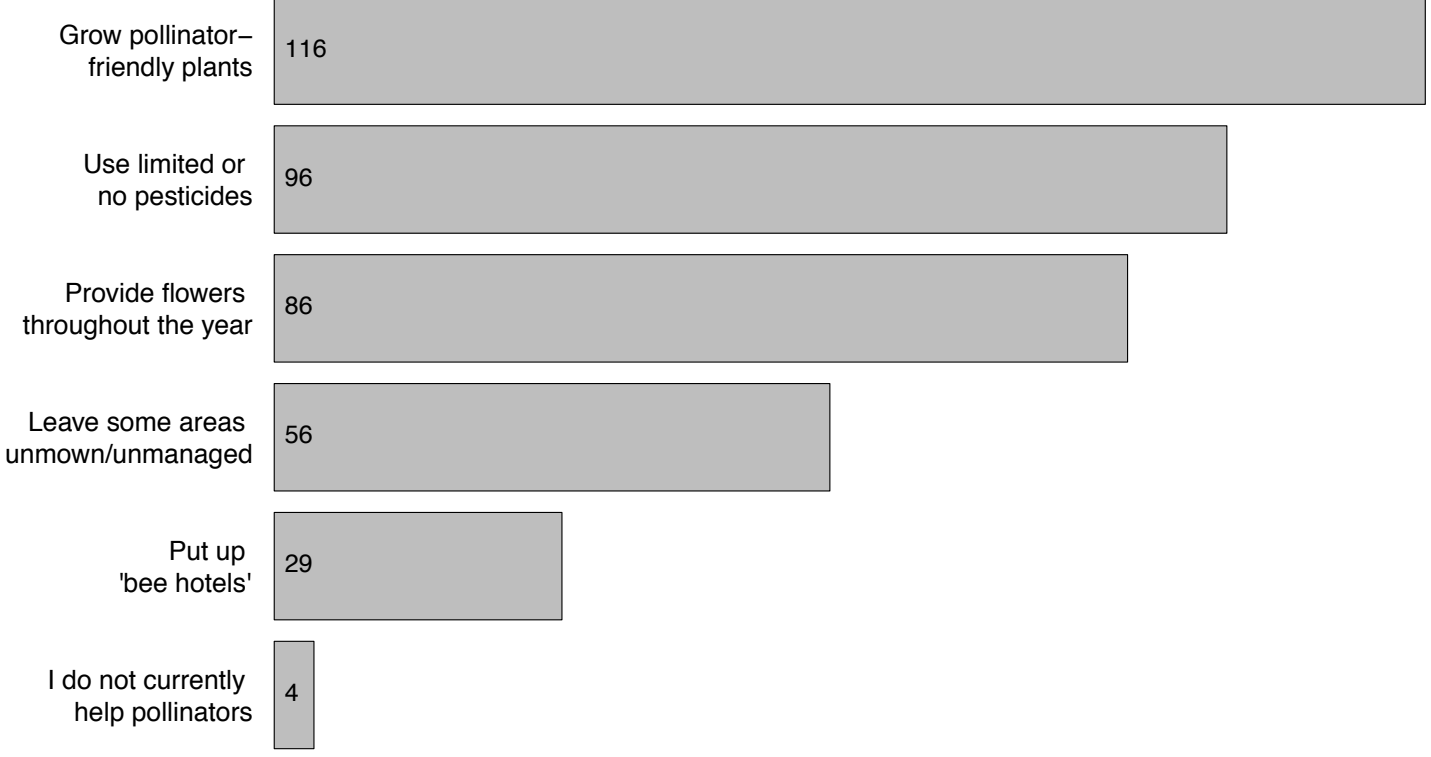

(b) Q14. If a plant has a "pollinator-friendly" label would you be more inclined to buy that plant?

96

Yes

Maybe

48

No

6

(c) Q16. Do you think garden centres offer enough information about which plants are good for bees and other pollinators?

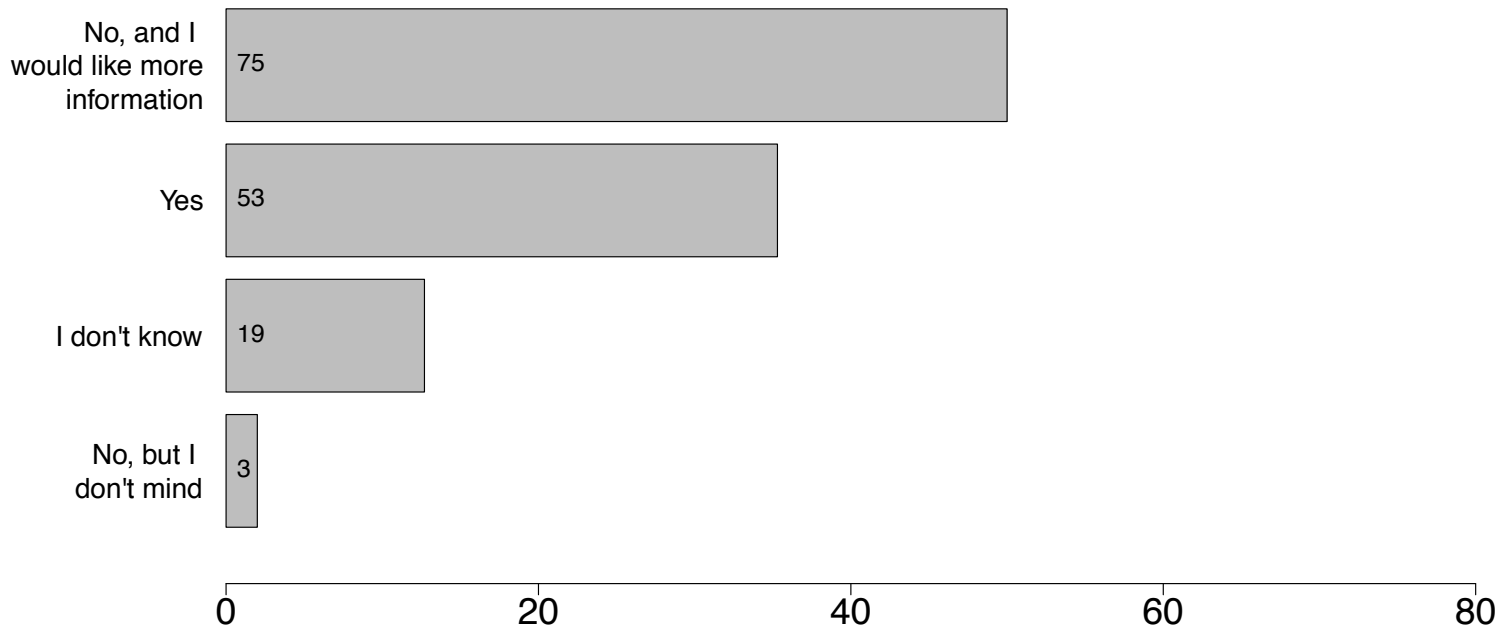

